\title{
Beyond Absolutism: Guiding Principles Needed for Humanitarian Medicine: Letter to the Editor
}

\author{
Ira L. Leeds
}

Published online: 1 May 2010

(C) Société Internationale de Chirurgie 2010

To the Editor:

In their article in the March issue of this journal, Welling et al. [1] performed an admirable job highlighting many of the common pitfalls of humanitarian biomedical interventions and developed a series of prescriptive warnings of specific faults that should be avoided. The accompanying commentary [2] further commends the authors for their unique perspective as both physicians and members of the United States military. In their effort to caution how humanitarian medicine can cause more harm than good, however, the authors may have overstated their argument. An important unmentioned premise of humanitarian interventions is that these ventures are rarely wholly good or bad. These projects typically fall into legal and ethical gray areas that deserve qualification rather than absolute judgments of right or wrong.

Welling et al. [1] frame their argument by comparing common humanitarian mistakes to the medieval concept of cardinal sins. By definition, cardinal sins were errors in action or thought that were never justifiable. This concept of moral absolutism seems an inappropriate metaphorical device for the complex relativism inherent to most humanitarian work. The disordered chaos that characterizes most humanitarian crises invites moral ambiguity, and ethical commandments that attempt to dismiss this intrinsic complexity grossly oversimplify the reality of work on the ground. For example, the authors note that politics and medical training often distract from the real "service" component of humanitarian biomedical interventions. To attempt to separate these various elements seems

I. L. Leeds $(\bowtie)$

Emory Medishare, Emory University School of Medicine,

Atlanta, GA, USA

e-mail: ileeds@emory.edu unrealistic and efforts to decouple indirect benefits of humanitarian work from direct service provision may distract from the greater purpose of undertaking such projects in the first place. Given that most humanitarian work requires institutional support (e.g., military, university, faith-based organizations), there will always be special interests beyond direct service that must be evaluated and managed appropriately. But trying to eradicate these secondary objectives is very likely impossible and could very well alienate many of the organizations that currently support such service efforts.

Planning and implementing effective and appropriate biomedical humanitarian interventions is fraught with obstacles. Rather than crafting a series of "thou shalt nots" for medical humanitarians, what the greater community needs is a consensus-driven framework for humanitarian intervention. Lists of common mistakes are helpful, but guiding principles that encompass the clinical, educational, logistical, and ethical-legal issues surrounding medical humanitarianism are dearly needed. Such guidelines would recognize the inherent problems of these interventions and provide realistic guidance to managing the complexity and moral ambiguity of such work.

\section{References}

1. Welling DR, Ryan JM, Burris DG et al (2010) Seven sins of humanitarian medicine. World J Surg 34:447-470

2. Schein M (2010) Sevens sins of humanitarian medicine. World J Surg 34:471-472 